Check for updates

Cite this as: $B M J$ 2020;371:m4122 http://dx.doi.org/10.1136/bmj.m4122 Published: 26 October 2020

\section{The surgeon solving violent crime with data sharing}

We have amended this article (BMJ 2020;371:m2987, doi:, published 14 October 2020) to remove the sentence, "And a recent study looking to replicate the model in the southeastern US found that, for every \$1 (78p; €..85) spent, the Cardiff model would save \$15 in the health system and \$19 in criminal justice.”

The US Centers for Disease Control and Prevention (CDC) has clarified that it did not perform a separate cost-effectiveness evaluation, just a process evaluation. The figures in the removed sentence were in the report but were a conversion from the UK model figures appearing in the Florence et al paper cited in this article as reference 6 . 